\title{
WHEN A FAMILY MEMBER HAS A SCHIZOPHRENIC DISORDER: Practice Issues Across the Family Life Cycle
}

\author{
Layne K. Stromwall, Ph.D., and Elizabeth A.R. Robinson, Ph.D.
}

Viewing individuals with schizophrenic disorders within a family life-cycle context promotes recognition of the range of family roles, particularly partnership and parenting roles, in clients' lives. Knowledge of clients' stage of family development allows practitioners to view the client more holistically - as a family member with roles and responsibilities-instead of as an isolated, ill individual. Gender differences-in family roles and in manifestation of the illness-are considered.

$\mathrm{B}$ efore deinstitutionalization, individuals who developed schizophrenic disorders typically spent large parts of their lives after diagnosis in mental hospitals, where institutional rules prohibited the social bonds of intimate, conjugal relationships and active parenthood. Court decisions enforcing both the legal right to receive treatment in a nonrestrictive environment and stricter standards for involuntary commitment, combined with the increasing cost of institutional care, resulted in a major shift in the environmental context in which those with schizophrenic disorders live (Mechanic, 1989). As the locus of treatment for schizophrenia changed from the institution to the community, people with schizophrenic disorders gained increased access to normative human relationships and the social roles and developmental tasks that accompany them. Researchers have also noted the variable course and stability of schizophrenic disorders across the life cycle (Adler et al., 1995).
Most people living in the community form intimate partnerships, marry, and rear children in adulthood. Society expects adults to have such relationships and roles, which are well understood to be gendered (McGoldrick, Anderson, \& Walsh, 1989). The interaction of gendered societal role expectations and schizophrenia is further complicated by gender differences in the manifestation of schizophrenic disorders (Goldstein, 1993; Seeman, 1988). Gender differences observed in clinical studies of schizophrenia include age at onset, symptoms, treatment outcome, and social functioning. These gender differences are critical factors in understanding the social behavior and relationships that form the family context of individuals with schizophrenic disorders.

In this paper, a life-cycle model that delineates normative family transitions and tasks, drawn from the work of Carter and McGoldrick (1989) and that of Rolland (1994), is extended to schizophrenia to con- 
ceptualize its varied impact on individuals and families at different life stages. Because researchers have found significant differences in the ways in which men and women experience schizophrenic disorders, the model will also be used to assess the differential impact on women's and men's familial roles. The literature on gender differences in schizophrenia will be reviewed briefly, and implications for the family life cycle and for clinical practice will be examined.

\section{GENDER DIFFERENCES}

\section{Age at Onset}

Researchers have consistently found an earlier onset of schizophrenia in men. More men than women appear to develop the disorder at an early age, and more women than men develop the disease later in adulthood (Goldstein, 1993). The NIMH Epidemiologic Catchment Area (ECA) Wave I study, a nationwide community-based random sample of households and institutions, found a mean age at onset of 19.9 years for all people meeting DSM-III diagnostic criteria for schizophrenia (Keith, Regier, \& Rae, 1991). The age of onset for women appeared to lag three to four years behind that of men until age 37. Age at first inpatient treatment is also lower for men. In a review of 53 studies from around the world, men had a mean age at first admission to a psychiatric facility that was more than eight years earlier than that of women (29.9 and 38.8 years, respectively) (Angermeyer \& Kuhn, 1988). Men's earlier age at onset probably explains why acute psychiatric services see more young men for first treatment (Hafner, Maurer, Loffler, \& Riecher-Rossler, 1993).

The development of the disease after the age of 45 , typically termed late-onset schizophrenia, is significantly more common in women (Castle, Wessely, \& Murray, 1993). Harris and Jeste (1988) reviewed 30 European studies of late-onset schizophrenia and found that female patients predominated in those who developed schizophre- nia after the age of 45 . The clinical profile of late-onset schizophrenia includes more paranoid symptoms.

\section{Manifestations and Symptoms}

Despite the differences in age at onset, the prevalence of schizophrenic disorders appears equal in both genders (Keith et al., 1991). However, men and women appear to experience the disease differently. Behavioral evidence suggests that young males seem especially prone to a severe neurodevelopmental form of schizophrenic illness associated with psychosocial problems occurring before the development of diagnosable symptoms. Men with onset before the age of 25 have a higher incidence of severe schizophrenia of long duration and a greater association with poor social functioning before diagnosis (Castle et al., 1993). However, women who develop the disease before the age of 25 have also been observed to show more severe symptoms than women who develop the disease later (Test, Burke, \& Wallisch, 1990).

Several lines of research seek to explain the different manifestations. Lewine (1981) proposed a model that attributes gender differences to two subtypes of the disease, one that generally affects men and one that primarily affects women. Goldstein and Tsuang (1990) suggested that gender places individuals at differing risks for developing the disease. Seeman (1988) hypothesized that women's biochemistry, primarily higher levels of estrogen, assists antipsychotic medication to mediate symptoms.

\section{Functioning}

Overall, women appear to have better treatment outcomes. They are less likely than men to be rehospitalized, have shorter lengths of stay if they return to the hospital, and remain in the community longer $(A n-$ germeyer, Goldstein, \& Kuhn, 1990; Goldstein, Tsuang, \& Farina, 1989). Women display higher social functioning on admission and are more likely to be active in an occupational role and to be (and remain) 
married after treatment (Goldstein et al., 1989).

In a clinical sample, women with schizophrenic disorders were more likely than men to be parents, and they lived with and cared for their children for considerable periods (Test et al., 1990). However, most of the mothers in this study were single, separated, or divorced, suggesting that the financial and child care issues that concern the general population of single parents are also factors for women with schizophrenic disorders. Women with a serious mental illness reported experiencing high satisfaction with the parenting role, and felt confident in their parenting skills (Mowbray, Oyserman, \& Ross, 1995). The women identified many environmental barriers to effective parenting, such as lack of financial resources and lack of social support. Studies of the custody status of mentally ill mothers' children suggest that most of these mothers have had to relinquish parenting responsibility for at least some period (Coverdale \& Aruffo, 1989; Test et al., 1990).

Men and women have been found to differ in their formation of conjugal families. Using the ECA data, Keith et al. (1991) found that men with schizophrenic disorders were more likely than women to remain unmarried. However, when informal partnerships were included in a study of relationships using the same data, both men and women with schizophrenic disorders showed a high rate of partnership (Stromwall, 1996): $69 \%$ of men and $77 \%$ of women reported legal or informal partnerships at some time in their lives, and differences between the genders were not statistically significant. The partnerships were unstable, with more than $90 \%$ of those in relationships experiencing separation or divorce at some period.

\section{Do Women's Needs Differ From Men's?}

Differences in the way women and men develop and experience schizophrenic disorders suggest that more men than women will develop such a disorder while connected to their family of origin, whereas more women will develop the disorder after they have formed partnerships and become parents. Although the social roles of partnership and parenting appear to be of special importance to women, the family life-cycle stages are not gender-exclusive. If these roles have a disproportionate impact on women, it may be because their later age of onset and higher levels of functioning place them in later stages of the family life cycle. However, the lack of attention to the development of relationship skills has a disproportionate impact on those men who spend their adolescence and early adulthood struggling with severe schizophrenia.

\section{THE FAMILY LIFE CYCLE MODEL}

Current practice with respect to people with serious mental illness includes analysis of needs across normative life domains. It is the thesis of this paper that the domain of intimate family relationships can be readily and usefully described by means of a family life-cycle model (Carter \& McGoldrick, 1989; Rolland, 1994). Assessment of both individual and family functioning depends on knowledge of the current family life-cycle stage and its associated social roles and relationships within the family. Rolland's extension of the normative Carter and McGoldrick model to families in which one individual has serious physical health issues has been useful for developing this conceptualization of life-cycle stages in families in which a member has a schizophrenic disorder.

Lefley (1996) has also used Carter and McGoldrick's model for work with the seriously mentally ill, but her emphasis is on its implications for caregivers. The present paper will delineate a greater range and complexity of family roles. People with schizophrenic disorders are not only recipients of care; they take on normative familial roles: they care for their own children and parents at the same time as they are 
managing their psychiatric illness and benefiting from the caregiving roles of other family members.

\section{Schizophrenia's Impact}

The conceptual model presented in TABLE 1 delineates five major family life-cycle stages and the normative tasks associated with each. The last column describes the complexities the individual and family are likely to experience when the illness manifests during this stage.

Stage 1: Single young adults. Development of a schizophrenic disorder interferes with completion of the typical tasks of the young adult-formal education, development of a productive employment history, and acquisition of skills necessary to form and maintain partnerships and conjugal families. Because schizophrenia has halted their educational and vocational development, and because of an ongoing need for social support from family, young adults are less able to separate from the family of origin. The formation of fewer partnerships in this group may also result from the more severe form of schizophrenia typified by an earlier onset and reduced social competence (Goldstein, 1993). More men than women develop schizophrenic disorders at this stage, so the loss of early social experiences affects men disproportionately.

Family impact may include continued residence with the family of origin, financial support or need for health insurance coverage under a parent's policy, caregiving, and social support. The social withdrawal that characterizes schizophrenia's negative symptoms undermines the development of intimate partnerships that typically result in independent living. As normative social support systems shrink due to overt symptoms and stigma, the opportunity for potential mates lessens. If an individual experiences an acute schizophrenic episode while in the first stages of a relationship, it is likely that the relationship will end. Just as families of origin are dis-

\section{Table 1}

\section{STAGES OF THE FAMILY LIFE CYCLE IN SCHIZOPHRENIC DISORDERS}

\section{STAGE}

1. Single Young Adults

2. Forming Partnerships

3. Families with Young Children

4. Families with Adolescents

5. Families with Adult Children

\section{DEVELOPMENTAL TASKS}

Seperation from family of origin. Development of peer-, work-, partnership relationships.

Formation of conjugal system. Extended family includes partner.

Welcome children to conjugal relationships.

Take on child-rearing, financial, household tasks.

Extended family to include children.

Nuclear family allows adolescent flexible boundaries.

Parent focus on mid-life issues.

Care for older generation.

Renewal of partnership.

Development of adult relationships with children.

Extended family includes child's partner.

\section{IMPACT OF DISORDER}

Parents involved with young adult child.

New partner with schizophrenic disorder has difficulty devoting energy to dyad.

Partner w/out disorder may lose commitment.

Young partner with schizophrenic disorder may have difficulty relating to/caring for child.

Partner must take on more responsibility for all adult roles in household.

Young child's needs not optimally met.

Parent with schizophrenic disorder needs care and support from partner and children.

Partner's expectations for relief of caregiving not met.

Adolescent child must take on adult roles.

Parent with disorder has continued need for support from partner and young adult child; separation difficult.

Young adult child may not admit potential partners to family due to stigma. 
tressed by symptoms, so too are potential partners who choose to end a nascent relationship. Shrinking support systems of individuals and families result in greater demands on the family itself.

Stage 2: Forming partnerships. Those who experience the onset of schizophrenic disorders after entering into committed relationships can be predicted to have problems in the formation of their conjugal family (Anderson \& Holder, 1989). The overwhelming demands of the schizophrenic disorder, like those of any illness, may reduce the amount of emotional energy available to partners in forming a durable bond. Simultaneously, stress over the well partner's long-term commitment to the relationship may affect psychiatric outcome. Anderson and Holder have identified stress arising from relationship issues as a particular problem for women with schizophrenic disorders.

In both Stage 1 and Stage 2, women have reproductive health needs that may be missed by mental health systems. Women typically develop the disease three to four years later than men, giving women more time to complete the developmental tasks of separating from the family of origin, completing education, beginning a work history, and forming an independent social support system. Many have already taken on the developmental tasks of partnership and formation of their own household before developing their illness. Women who develop schizophrenia in either of these stages have more opportunity to assume and complete developmental tasks after the onset of symptoms because of women's generally higher functioning (Goldstein \& Tsuang, 1990). Thus, clinicians should note that women with schizophrenic disorder have the same needs for reproductive health care as do all women at this time of life (Coverdale \& Aruffo, 1989; Handel, 1988), an issue too rarely addressed in mental health settings.

As new partnerships form, more people are affected by the illness. When a spouse develops a chronic or life-threatening physical illness, society expects the partner to remain supportive. However, when a spouse develops a psychiatric illness, the partner may not feel the same social obligation. Stigma and lack of information about the disorder may provide reasons for the partner to abandon the relationship. For example, the partner may be confused by symptoms, without understanding their source, or may attribute the symptoms to normative concerns, such as relationship, parenting, or work problems. Where relationship difficulties have been present in the past, or where the spouse projects blame, the partner may even feel responsible for the spouse's symptomatic behavior.

Stage 3: Families with young children. Here, individuals begin families by bearing children and caring for them. Early in the process, parents typically experience high stress when the intense demands of young children are added to the burdens of employment and the need to develop a social network. More women than men develop a schizophrenic disorder after becoming parents because of their later age at onset. However, there is considerable evidence that these women do not receive much support from either the mental health or child welfare systems for their existing roles as parents (Apfel \& Handel, 1993; Bachrach, 1988a, 1988b; Coverdale \& Aruffo, 1989; Mowbray, Oyserman, \& Zemencuk, 1995; Zemencuk, Rogosch, \& Mowbray, 1995). Since stress is a factor in the management of mental disorder, services and supports for parents with schizophrenia are greatly needed.

Those with onset of schizophrenic disorders before this stage may also become parents. Obtaining needed services outside the mental health system can be problematic when service providers do not understand the disorder. Negotiating the health care system for support during pregnancy and childbirth is an issue of particular concern for women (Mowbray et al., 1995; Rudolph, Larson, Sweeny, Hough, \& Aror- 
ian, 1990). Both men and women must deal with the child protective service system when issues arise regarding their ability to parent (Nicholson \& Blanch, 1995; Zemencuk et al., 1995). These parents must often weigh the need for inpatient treatment of a developing schizophrenic disorder against the need to remain in the household and care for children. Faced with the prospect of leaving home and relinquishing responsibility for their children, parents may resist treatment.

Studies of mothers with a mental illness have identified many environmental barriers to effective parenting, such as lack of financial resources and social supports (Mowbray et al., 1995). Many mothers with a mental illness appear to have relinquished parenting responsibility for at least some period (Coverdale \& Aruffo, 1989; Test et al., 1990). Child protective service workers in a California study estimated that $60 \%-75 \%$ of mentally ill mothers referred to their department would lose custody of their children (Bazar, 1990). The circumstances around loss of custody, and whether loss of custody results in loss of contact with the child, are less clear (Mowbray et al., 1995).

When the person with the schizophrenic disorder has been the primary caregiver for the family's young children, the partner must assume these responsibilities or seek the assistance of extended family or outside services. Partners who are faced with taking on many roles typically shared by adults in the household (e.g., financial support, child care, maintaining the home, community involvement) may experience the stresses common to single parenthood, in addition to the burden of caring for the ill spouse. The presence of young children in the family can affect decisions about staying in the relationship: perceptions of the illness's effect on children can become reasons for sustaining or dissolving the relationship.

Young children may find their environment chaotic and inexplicable if the par- ent's symptoms include overt delusions or frequent hallucinations (Webster, 1992). The parent with a schizophrenic disorder may have trouble both relating to and caring for a child, depending on the unique characteristics of the disorder. In some cases, symptoms may cause behavior that is interpreted as (or actually is) dangerous to the child. Simultaneously, beliefs about the capacities of individuals with schizophrenia affect decisions about parenting capabilities. Family members or outside authorities may believe that schizophrenia prevents effective parenting in all situations, even when symptoms are well managed. Well intended but overly cautions interventions, including the removal of children from parents when it is unwarranted, can cause permanent suffering for all parties.

Stage 4: Families with adolescent children. In this stage, parents normally expect some relief from intense demands of young children. They also expect time for renewal of the spousal relationship. As is common with any chronic illness, schizophrenia interferes with normative expectations. Adolescent children who do not understand the nature of the psychiatric disability, or who experience social stigma, may reject the parent. Consequently, just when the person with a schizophrenic disorder needs more support from the partner and child, there may be less available - or it may come at significant cost to the relationship.

Parents of adolescent children may also care for older relatives. When a psychiatric disorder prevents or limits their caring for elders, women in this stage of the family life cycle may experience feelings of guilt or inadequacy. Caregiving roles with regard to these elders may not be abandoned, however, and the stress of undertaking them may contribute to psychiatric outcome.

For the partner, child care demands may be reduced, but continued care for the disabled partner adds to relationship stress. Normative caring for the older generation 
further compounds the stressors at this stage. Partners who earlier had chosen to maintain the family system for the sake of the children, may find their motivation to be weaker at this stage, making divorce or separation more likely.

Adolescent children's normative needs to separate from the family can be undermined if the parent requires assistance. The family may expect the adolescent to take on caregiving and other adult roles in the household. Adolescents in these circumstances may also withdraw from peer relationships due to stigma. They may forgo educational or vocational objectives in order to remain at home, particularly if the parental relationship ends at this time. If the family does remain intact, its boundaries are likely to become more rigid, making it difficult for the young adult children to introduce their own partnership relationships into the extended family. In effect, the last two stages blur into one, as the family struggles with its developmental tasks.

Stage 5: Families with adult children. Here, the family shrinks to the partners and, in some cases, adult members (parents or children) who require care or support. Developmental tasks include renewal of the partnership, forging of adult relationships with children, and inclusion of adult children's partners in the extended family. Onset at this stage has particular implications for family life. The clinical profile of late-onset schizophrenia, beginning after the age of 45 , includes more paranoid symptoms. This symptom type can alienate the family and the support system, particularly if the paranoid beliefs are directed at them; e.g., the individual is suspicious of family members as a result of the disorder. Since more women than men develop a schizophrenic disorder during this family life-cycle stage, women may need support and care from adult children, as well as a partner with realistic expectations. The stigma of mental illness often precludes family members from behaving as they would when a mother develops any other chronic illness. The family can become more insular, moving away from natural support systems. Additionally, natural support systems themselves may withdraw due to misunderstanding of the nature of the disorder. For example, a friend may believe that accusations about the relationship are interpersonal difficulties when they are paranoid symptoms of schizophrenia. This set of dynamics exacerbates the difficulties of the person with schizophrenia in meeting her needs for connection with her partner, relations with her adult children, and inclusion of her children's partners in the family.

\section{IMPLICATIONS FOR PRACTICE}

Practitioners can use the family life cycle as a framework for assessment and evaluation, clinical interventions, and program planning in work with individuals with schizophrenic disorders. Services specific to different stages of the family life cycle include: information about partnership (Stage 2) and parenting (Stages 3, 4) roles, collaborative involvement of partners (Stages 1-4) and children (Stages 2-5) in psychoeducational programs and support groups, and collaboration between practitioners working in child welfare and in mental health.

Improving the ability of those with schizophrenic disorders to handle their roles as partners and parents through specific interventions may ease stress, foster more permanent relationship, and reduce the possibility of relapse. A focus on clients' family life-cycle stages broadens outcome beyond overt symptomatology, general social skills, and employment. Competent functioning in family roles is as important to clients as more traditional psychiatric outcomes. Family life-cycle assessment can also assist in identifying previously unrecognized strengths.

\section{Clinical and Programmatic Interventions}

Partnership. For both men and women, spousal relationships, often a key compo- 
nent of life satisfaction, involve issues of sexuality, sexual orientation, reproductive health, genetics, and choice of intimate partners. Although many psychosocial rehabilitation programs incorporate training in social skills that can enhance the ability to develop intimate relationships, such programs rarely cover such common concerns as coercion, sexual orientation, contraception, and sexually transmitted diseases. These can be critical issues for women who are susceptible to rape and for whom pregnancy has such significant implications. Additionally, potential parents may have concerns about the implications of the schizophrenic disorder that should be addressed in genetic counseling.

Just as people require specific skills to initiate and manage early stages of romantic relationships, they must call on different skills to maintain ongoing committed relationships. Supporting client efforts to acquire and employ clear communication strategies, reasonable expectations, and mutuality in decision-making is a key component in supporting their efforts to develop and maintain a partnering role.

With some exceptions (Mannion, Mueser, \& Solomon, 1994), psychoeducational programs for families are primarily oriented to clients' families of origin. The egalitarian nature of the partnership relationship and its voluntary commitment suggests that partners' needs are different from those of parents of adult children with schizophrenia. Although basic principles of illness management, communication, and problem-solving may remain the same, the social support component of psychoeducational programs can be enhanced by specific programs for partners.

Parenting. It is now generally agreed that practitioners should include all of the family members affected by schizophrenia in any assessment and evaluation effort. In particular, clients' children need attention as they learn to cope with the disruptions and differences in parenting. A parent's psychiatric disorder will not affect all chil- dren equally. Children's resilience when parenting is disrupted varies, as does these parents' degree of disability in the parenting role.

Among interventions for clients with schizophrenia that aim to build skills, few focus on parenting, although this is a highly valued role to those with psychiatric disorders (Nicholson \& Blanch, 1995). Existing efforts to enhance parenting skills (Webster-Stratton \& Herbert, 1994) could be incorporated to meet the specific needs of parents who have schizophrenia. These group-based interventions typically include both didactic information on child development and discipline strategies, as well as opportunities to practice new models of interaction with one's children. Parents with schizophrenic disorders may need additional assistance in developing support systems around their role as parents. Children can also be helped through psychoeducational interventions. Information, a supportive and encouraging adult, bibliotherapy, and group work can provide clients' children with needed help. Practitioners should tailor their content and format to meet the requirements of the child's developmental level and focus on the parent's particular symptoms and disability.

Traditionally, research on child rearing among the mentally ill was limited to clinical studies analyzing the effects of mothers' parenting deficits on the child's behavior or emotional health (Cohler \& Musick, 1984; Goodman \& Brumley, 1990; Webster, 1992). More recently, several articles have addressed parenting competency and needs from the point of view of the mentally ill mother (Mowbray et al., 1995; Oyserman, Mowbray, \& Zemencuk, 1994). In supporting the parenting role of clients with schizophrenia, mental health professionals should include collaboration and coordination with child welfare agencies. Child welfare workers who do not understand the nature of a parent's mental illness cannot appropriately support these families. In-service training in schizophrenia, 
particularly emphasizing variations in functioning and teaching skills in assessing dangerousness (Louis, Condon, Shute, \& Elzinga, 1997), could have a significant impact on clients and their children. At the same time, mental health practitioners who do not understand the value clients place on their parenting role cannot appropriately support their client's recovery.

\section{REFERENCES}

Adler, D.A., Pajer, K., Ellison, J.M., Dorwart, R., Siris, S., Goldman, H., Lehman, A., \& Berlant, J. (1995). Schizophrenia and the life cycle. Community Mental Health Journal, 31, 249-262.

Anderson, C.M. \& Holder, D. (1989). Women and serious mental disorders. In M. McGoldrick, C.M. Anderson, \& F. Walsh (Eds.), Women in families. New York: Norton.

Angermeyer, M.C., Goldstein, J.M., \& Kuhn, L. (1990). Gender and the course of schizophrenia: Differences in treated outcomes. Schizophrenia Bulletin, 16, 293-307.

Angermeyer, M.C., \& Kuhn, L. (1988). Gender differences in age at onset of schizophrenia. European Archives of Psychiatry \& Neurological Sciences, 237, 351-364.

Apfel, R., \& Handel, M. (1993). Madness and loss of motherhood: Sexuality, reproduction and longterm mental illness. Washington, DC: American Psychiatric Association.

Bachrach, L.L. (1988a). Chronically mentally ill women: An overview of service delivery issues. In: L. Bachrach \& C. Nadelson (Eds.), Treating chronically mentally ill women (pp. 3-17). Washington, DC: American Psychiatric Association.

Bachrach, L.L. (1988b). Emergence and legitimation of program issues. In L. Bachrach \& C. Nadelson (Eds.), Treating chronically mentally ill women (pp. 77-96). Washington, DC: American Psychiatric Association.

Bazar, J. (1990, December). Mentally ill moms aided in keeping their children. APA Monitor, 32.

Carter, E.A., \& McGoldrick, M. (Eds.) (1989). The changing family life cycle: A framework for family therapy (2nd ed.). Boston: Allyn \& Bacon.

Castle, D.J., Wessely, S., \& Murray, R.M. (1993). Sex and schizophrenia: Effects of diagnostic stringency, and associations with premorbid variables. British Journal of Psychiatry, 162, 658-664.

Cohler, B.J., \& Musick, J.S. (Eds.). (1984). Intervention among psychiatrically impaired parents and their young children. San Francisco: Jossey-Bass.

Coverdale, J.H., \& Aruffo, J.A. (1989). Family planning needs of female chronic psychiatric outpatients. American Journal of Psychiatry, 146, 1489-1491.

Goldstein, J. (1993). Sampling biases in studies of gender and schizophrenia: A reply. Schizophrenia Bulletin, 19, 9-14.
Goldstein, J., \& Tsuang, M. (1990). Gender and schizophrenia: An introduction and synthesis of findings. Schizophrenia Bulletin, 16, 179-183.

Goldstein, J., Tsuang, M., \& Farina, S.V. (1989). Gender and schizophrenia: Implications for understanding the heterogeneity of the illness. Psychiatry Research, 28, 243-253.

Goodman, S.H., \& Brumley, H.E. (1990). Schizophrenic and depressed mothers: Relational deficits in parenting. Developmental Psychology, 26, 31-39.

Hafner, H., Maurer, K., Loffler, W., \& RiecherRossler, A. (1993). The influence of age and sex on the onset and early course of schizophrenia. British Journal of Psychiatry, 162, 80-86.

Handel, M.H. (1988). Deferred pelvic exams: A purposeful omission in the care of mentally ill women. In L. Bachrach \& C. Nadelson (Eds.), Treating chronically mentally ill women. (pp. 99-110). Washington, DC: American Psychiatric Association.

Harris, M., \& Jeste, D. (1988). Late onset schizophrenia: An overview. Schizophrenia Bulletin, 14, 39-55.

Keith, S.J., Regier, D.A., \& Rae, D.S. (1991). Schizophrenic disorders. In L.N. Robins \& D.A. Regier (Eds.), Psychiatric disorders in America: The epidemiologic catchment area study (pp. 33-52). New York: Free Press.

Lefley, H.P. (1996). Family caregiving in mental illness. Newbury Park, CA: Sage.

Lewine, R. (1981) Sex differences in schizophrenia: Timing or subtypes? Psychological Bulletin, 90. $432-444$.

Louis, A., Condon, J., Shute, R., \& Elzinga, R. (1997). The development of the Louis MACRO (Mother and Child Risk Observation) forms: Assessing parent-infant-child rist in the presence of maternal mental illness. Child Abuse \& Neglect, $21,589-606$.

Mannion, E., Mueser, K., \& Solomon, P. (1994). Designing psychoeducational services for spouses of persons with serious mental illness. Community Mental Health Journal, 30, 177-190.

McGoldrick, M., Anderson, C.M., \& Walsh, F. (1989). Women in families: A framework for family therapy. New York: Norton.

Mechanic, D. (1989). Mental health and social policy (3rd ed.). Englewood Cliffs, NJ: Prentice Hall.

Mowbray, C.T., Oyserman, D., \& Ross, S. (1995). Parenting and the significance of children for women with a serious mental illness. Journal of Mental Health Administration, 22, 189-200.

Mowbray, C.T., Oyserman, D., \& Zemencuk, J. (1995). Motherhood for women with serious mental illness: Pregnancy, childbirth, and the postpartum period. American Journal of Orthopsychiatry. 65, 21-38.

Nicholson, J., \& Blanch, A. (1995). Rehabilitation for parenting roles for people with serious mental illness. Psychosocial Rehabilitation Journal, 18(I), $109-119$.

Oyserman, D., Mowbray, C.T., \& Zemencuk, J.A. (1994). Resources and supports for mothers with severe mental illness. Health and Social Work, 19, 132-142. 
Rolland, J.S. (1994). Families, illness and disability: An integrative treatment approach. New York: Basic Books.

Rudolph, B., Larson, G., Sweeny, S., Hough, E., \& Arorian, K. (1990). Hospitalized pregnant psychotic women: Characteristics and treatment issues. Hospital and Community Psychiatry, 41, 159-162.

Seeman, M. (1988). Schizophrenia in women and men. In L. Bachrach \& C. Nadelson (Eds.), Treating chronically mentally ill women (pp. 19-28). Washington, DC: American Psychiatric Association.

Stromwall, L.K. (1996). Gender differences in the social roles of parent and partner: The case of women and men with schizophrenic disorders. Unpublished doctoral dissertation, Case Western Reserve University, Cleveland.
Test, M., Burke, S., \& Wallisch, L. (1990). Gender differences of young adults with schizophrenic disorders in community care. Schizophrenia Bulletin, 16, 331-344.

Webster, J. (1992). Split in two: Experiences of the children of schizophrenic mothers. British Journal of Social Work, 22, 309-329

Webster-Stratton, C., \& Herbert, M. (1994). Troubled families-problem children: Working with parents: A collaborative process. New York: John Wiley.

Zemencuk, J., Rogosch, F., \& Mowbray, C.T. (1995). The seriously mentally ill woman in the role of parent: Characteristics, parenting sensitivity, and service needs. Psychosocial Rehabilitation Journal, 18(3), 79-92. 